\title{
Risk conditions in healthcare workers of a pediatric COVID center in Mexico City
}

\author{
Horacio Márquez-González¹, Miguel Klünder-Klünder ${ }^{*}$, Daniela de la Rosa-Zamboni², \\ Fernando Ortega-Riosvelasco ${ }^{3}$, Briceida López-Martínez ${ }^{3}$, Guadalupe Jean-Tron ${ }^{1}$, Gina Chapa-Koloffon ${ }^{1}$, \\ A. Viridiana Ávila-Hernández ${ }^{1}$, Juan Garduño-Espinosa ${ }^{1}$, Mónica Villa-Guillén ${ }^{4}$, and Jaime Nieto-Zermeño ${ }^{5}$ \\ ${ }^{1}$ Dirección de Investigación; ${ }^{2}$ Epidemiología Clínica; ${ }^{3}$ Recursos Auxiliares de Diagnóstico; ${ }^{4}$ Dirección Médica; ${ }^{5}$ Dirección General. Hospital Infantil \\ de México Federico Gómez, Mexico City, Mexico
}

\begin{abstract}
Background: The new evere acute respiratory syndrome coronavirus 2 (SARS-CoV-2) is characterized by its high capacity to transmit. Health-care personnel is highly susceptible to becoming infected. This study aimed to determine the characteristics and known risk factors for contagion and severe outcomes of SARS-CoV-2 disease in health-care personnel of a pediatric coronavirus disease (COVID) center in Mexico City. Methods: In the last week of March 2020 (at the beginning of phase 2 of the Ministry of Health's national campaign in Mexico), a study was conducted on healthcare workers of a pediatric COVID hospital in Mexico City. Using a virtual interview, we evaluated comorbidities, mobility, areas and functions where they carry out the activities, protection measures, contact history, and vaccination. According to their activities, healthcare workers were classified into the following areas: medical, nursing, other health-care personnel (researchers, nutritionists, rehabilitation, imaging, and laboratory), administrative, and other services. We compared the variables between the groups of healthcare workers with the $X^{2}$ test. Results: We included 812 participants. The mean age was $41 \pm 11$ years, and $33 \%$ were overweight or obese, $18 \%$ were over 60 years old, and 19\% had high blood pressure. Medical and nursing personnel presented a higher proportion in the use of standard protection measures. Conclusions: Among healthcare workers, there are risk conditions for the development of complications in case of SARS-CoV-2 infection. Most medical and nursing personnel use standard protective measures.
\end{abstract}

Key words: Coronavirus disease-19. Healthcare workers. Pediatrics. Personal protective equipment. Mexico.

\section{Condiciones de riesgo en el personal de salud de un centro COVID pediátrico de la Ciudad de México}

\section{Resumen}

Introducción: La pandemia por el nuevo coronavirus 2 del síndrome respiratorio agudo grave (SARS-CoV-2) se caracteriza por su alta capacidad de transmitirse, por lo que el personal de salud es muy susceptible de contagiarse. El objetivo de este estudio fue determinar las características y los factores de riesgo conocidos para el contagio y los desenlaces graves

\section{Correspondence:}

*Miguel Klünder-Klünder

E-mail: klunderk@gmail.com

(http://creativecommons.org/licenses/by-nc-nd/4.0/).
Available online: 19-01-2021 Bol Med Hosp Infant Mex. 2021;78(2):110-115

www.bmhim.com 
de la enfermedad por SARS-CoV-2 en personal de salud de un centro COVID pediátrico de la Ciudad de México. Método: La última semana de marzo de 2020 (al inicio de la fase 2 de la campaña nacional por coronavirus en México) se realizó un estudio en los trabajadores de la salud de un hospital COVID pediátrico de la Ciudad de México. Mediante una entrevista virtual se evaluaron comorbilidad, movilidad, área y funciones donde se desempeñan las actividades laborales, medidas de protección, antecedentes de contactos y vacunación. Los participantes fueron clasificados en las siguientes áreas: personal médico, enfermería, otro personal de salud (investigadores, nutriólogos, rehabilitación, imagenología, laboratorio), administrativo y otros servicios. Se realizaron comparaciones de las variables con prueba de $X^{2}$ entre los grupos de trabajadores de la salud. Resultados: Se incluyeron 812 participantes. El 33\% presentó sobrepeso u obesidad, el 18\% eran mayores de 60 años y el 19\% tenía hipertensión arterial. El personal médico y de enfermería mostró una mayor proporción de uso de medidas de protección estándar. Conclusiones: Existen condiciones de riesgo para el desarrollo de complicaciones en los trabajadores de la salud en caso de contagio con SARS-CoV-2. La mayoría del personal médico y de enfermería utiliza las medidas de protección estándar.

Palabras clave: COVID-19. Trabajadores de la salud. Pediatría. Equipo de protección personal. México.

\section{Introduction}

In 2020, a new strain of coronavirus called severe acute respiratory syndrome coronavirus 2 (SARS-CoV-2) reached pandemic proportions quickly. This pandemic subjugated all the nations, evidencing the ease with which respiratory viruses can distribute among humans and collapse healthcare systems.

In the first half of June, more than 8 million people were infected with SARS-CoV-2, and nearly 500,000 lives have been lost due to severe complications'. Population density, hygiene, and exposure to infected persons have been identified as risk factors for contagion $^{2}$. In turn, advanced age, comorbidities such as systemic arterial hypertension (SAH), diabetes mellitus (MD), and obesity have been identified as poor prognostic factors. To the present date, there is no proven cure in terms of efficacy and safety ${ }^{3}$.

In this context, each nation's health-care systems have developed strategies that range from massive isolation to hospital facilities' reconversion into coronavirus disease (COVID) centers. As a result, COVID-19 has become especially significant among healthcare personnel. The most critical factor for imminent risk of contagion is the direct and continuous exposure to patients with the confirmed disease ${ }^{4}$.

Furthermore, it has been evident that the distribution of personal protection equipment is difficult due to the increased demand and handling difficulties. Significantly, the pediatric population's attention represents a greater risk of contagion because children manifest mild symptoms and, therefore, it is difficult to identify these patients ${ }^{5}$.

In Mexico, since the first case was confirmed in February 2020, strategies have been established for the reconversion of secondary and tertiary hospitals into COVID centers, and few single-specialty hospitals have maintained this status, especially those that serve the pediatric population. In this context, the Secretaria de Salud (Mexican Ministry of Health) implemented the strategic phase 3 due to the exponential increase in cases in which the population was massively sheltered at home, paralyzing most of the work activity ${ }^{6}$. As expected, the increased demand for healthcare was accompanied by an increased infection rate among healthcare workers. Thus, it is imperative to recognize healthcare workers' general conditions in COVID centers, identify areas for improvement to avoid the paralysis of care services due to contagion, and minimize the loss of human lives.

The present work describes a tertiary level pediatric hospital's situation arranged as a COVID center 1 week before phase- 3 activation. The objective was to determine the characteristics and known risk factors for SARS-CoV-2 infection and severe disease outcomes in health-care personnel of a pediatric COVID center in Mexico City.

\section{Methods}

The local institutional Research Ethics Committee approved the protocol. In this paper, we present the initial assessment of a cohort of healthcare workers from a National Institute of Health in Mexico City classified as a COVID center, which was integrated 1 week before the Ministry of Health initiated phase- 3 of the national contingency for the COVID-19 pandemic. Healthcare workers from the Hospital Infantil de México Federico Gómez (HIMFG) were invited to participate voluntarily in the study through official communications from the authorities and electronic media, and directly by the Epidemiology Service. We collected the 
information from the following personnel: medical staff, nursing staff, other health-care personnel (including researchers, chemists, and radiologic technologists), administrative staff (office work), and service providers (cleaning, security, or maintenance). Each person agreed to sign an informed consent form and complete an electronic questionnaire. Exclusion criteria included those who repeated the form with different answers or misidentified themselves, those on work leave, stays, or disability for other reasons at the recruitment time.

The electronic questionnaire included a section for the worker's identification, the service's characteristics, and contact details for the follow-up in the original protocol's subsequent phases.

Based on literature review, data on the following known risk factors were collected: age ( $>60$ years were considered at risk), obesity or overweight (body mass index [BMI] was calculated from the reported weight and height. Any result $>25 \mathrm{~kg} / \mathrm{m}^{2}$ was classified as overweight and $>30 \mathrm{~kg} / \mathrm{m}^{2}$ as obesity), SAH, DM, oncological history, chronic obstructive pulmonary disease (COPD), and asthma. Another section recorded vaccinations in the last year (influenza, pneumococcal, and tetanus).

Work activities were divided into the following categories: services provided in the COVID area (classification, emergencies, respiratory triage, intensive care, neonatal therapy, and COVID hospitalization section), care in non-COVID areas (disease-free patient sections), telecommuting or home office, and if the worker declared to provide services to other hospitals.

Furthermore, we corroborated if the participants had already presented COVID-19 (confirmed by the polymerase chain reaction test), if they had been contacts of confirmed cases (patients, other health personnel, or relatives), or if they were excluded (by a confirmatory test). The epidemiology service of the hospital ratified this information.

Another section of the questionnaire collected information about using personal protective measures at work during the last month: safe distance, hand washing, use of mask, gloves, or glasses. In addition, we asked about means of transportation used to get from home to the workplace (the hospital), including the following options: car, carpooling, cab (including those requested by application), walking, or any public transportation (subway, Metrobus, trolley, truck, and suburban).

\section{Statistical analysis}

Quantitative variables (weight, height, age, and BMI) were expressed as means and standard deviation,
Table 1. Demographic data of the participants

\begin{tabular}{l|c|c|}
\hline \multirow{2}{*}{ Variables } & \multicolumn{2}{|c|}{$\mathbf{n = 8 1 2}$} \\
\cline { 2 - 3 } & Frequency & $\%$ \\
\hline Sex & & \\
Male & 183 & 23 \\
Female & 629 & 77 \\
\hline Age (years) & $41 \pm 11$ & \\
BMl (kg/m²) & $30 \pm 5$ & \\
\hline Schooling & & \\
High school & 105 & 13 \\
Bachelor's degree & 324 & 40 \\
Postgraduate & 232 & 28 \\
Master's degree & 89 & 11 \\
Doctoral degree & 57 & 7 \\
Engineering & 5 & 1 \\
\hline Personnel classification & & \\
Medical staff & 153 & 19 \\
Nursing staff & 411 & 51 \\
Other healthcare personnel & 72 & 9 \\
Administrative staff & 140 & 17 \\
Security/cleaning staff & 36 & 4 \\
\hline
\end{tabular}

*Mean \pm standard deviation. BMI: body mass index.

while qualitative variables as frequencies and percentages.

A comparative analysis between groups was carried out. We used the $X^{2}$-test to analyze the differences. $p$-value $<0.05$ was considered statistically significant.

In addition, a chordal plot was used to describe mobility, contacts, and protection measures against infection (chords represent the variables of interest and the threads describe the percentage by category).

We used the Google forms software to elaborate the questionnaires, the SPSS version 2.0 software for MAC of $\mathrm{IBM}^{\circledR}$ for the statistical analysis, and the Chordal plot software for the chordal plot.

\section{Results}

During the study, 830 questionnaires were answered. We excluded 18 questionnaires due to incomplete records (10), inconsistent identification data (5), and repeated questionnaires (3).

In 812 participants, the mean age was $41 \pm 11$ years: $629(77 \%)$ were female (Table 1). In $324(40 \%)$, the educational level was a bachelor's degree. Of the total, $153(19 \%)$ were medical staff, $411(51 \%)$ were nurses, $72(9 \%)$ were other healthcare personnel, $140(17 \%)$ were administrative staff, and $36(4 \%)$ were security/ cleaning personnel. 
Table 2. Comparison of personal and occupational risk factors for SARS-CoV-2 infection or its severe presentations

\begin{tabular}{|c|c|c|c|c|c|c|c|c|c|c|c|}
\hline \multirow[t]{3}{*}{ Variables } & \multirow{2}{*}{\multicolumn{2}{|c|}{$\begin{array}{c}\begin{array}{c}\text { Medical } \\
\text { staff }\end{array} \\
153\end{array}$}} & \multirow{2}{*}{\multicolumn{2}{|c|}{$\begin{array}{c}\begin{array}{c}\text { Nursing } \\
\text { staff }\end{array} \\
411\end{array}$}} & \multirow{2}{*}{\multicolumn{2}{|c|}{$\begin{array}{c}\begin{array}{c}\text { Other healthcare } \\
\text { personnel }\end{array} \\
72 \\
\end{array}$}} & \multirow{2}{*}{\multicolumn{2}{|c|}{$\begin{array}{c}\begin{array}{c}\text { Administrative } \\
\text { staff }\end{array} \\
140\end{array}$}} & \multirow{2}{*}{\multicolumn{2}{|c|}{$\begin{array}{c}\begin{array}{c}\text { Security/ } \\
\text { cleaning staff }\end{array} \\
36\end{array}$}} & \multirow[t]{3}{*}{ p-value } \\
\hline & & & & & & & & & & & \\
\hline & n & $\%$ & n & $\%$ & $n$ & $\%$ & n & $\%$ & $n$ & $\%$ & \\
\hline $\begin{array}{l}\text { Medical history } \\
\text { Age }>60 \text { years } \\
\text { Systemic arterial hypertension } \\
\text { Diabetes mellitus } \\
\text { Overweight } \\
\text { Obesity } \\
\text { History of cancer } \\
\text { COPD/asthma }\end{array}$ & $\begin{array}{c}29 \\
39 \\
12 \\
30 \\
21 \\
2 \\
18\end{array}$ & $\begin{array}{c}19 \\
25 \\
8 \\
20 \\
14 \\
1 \\
12\end{array}$ & $\begin{array}{c}48 \\
70 \\
28 \\
32 \\
52 \\
7 \\
26\end{array}$ & $\begin{array}{c}12 \\
17 \\
7 \\
8 \\
13 \\
2 \\
6\end{array}$ & $\begin{array}{c}39 \\
19 \\
9 \\
7 \\
34 \\
2 \\
5\end{array}$ & $\begin{array}{c}54 \\
26 \\
13 \\
10 \\
47 \\
3 \\
7\end{array}$ & $\begin{array}{c}21 \\
27 \\
5 \\
48 \\
27 \\
1 \\
2\end{array}$ & $\begin{array}{c}15 \\
19 \\
4 \\
34 \\
19 \\
1 \\
1\end{array}$ & $\begin{array}{c}9 \\
3 \\
6 \\
18 \\
6 \\
0 \\
2\end{array}$ & $\begin{array}{c}25 \\
8 \\
17 \\
50 \\
17 \\
0 \\
6\end{array}$ & $\begin{array}{c}0.001 \\
0.05 \\
0.4 \\
0.001 \\
0.001 \\
0.8 \\
0.02\end{array}$ \\
\hline $\begin{array}{l}\text { History of vaccination in the last year } \\
\text { Pneumococcal } \\
\text { Influenza } \\
\text { Tetanus }\end{array}$ & $\begin{array}{c}115 \\
148 \\
70\end{array}$ & $\begin{array}{l}75 \\
97 \\
46\end{array}$ & $\begin{array}{c}92 \\
400 \\
120\end{array}$ & $\begin{array}{l}22 \\
97 \\
29\end{array}$ & $\begin{array}{l}15 \\
65 \\
15\end{array}$ & $\begin{array}{l}21 \\
90 \\
21\end{array}$ & $\begin{array}{l}10 \\
70 \\
12\end{array}$ & $\begin{array}{c}7 \\
50 \\
9\end{array}$ & $\begin{array}{c}6 \\
15 \\
3\end{array}$ & $\begin{array}{c}17 \\
42 \\
8\end{array}$ & $\begin{array}{c}0.001 \\
0.0001 \\
0.0001\end{array}$ \\
\hline $\begin{array}{l}\text { Risk activities* }^{*} \\
\text { Working in COVID areas } \\
\text { Care of patients in non-COVID areas } \\
\text { Home office } \\
\text { Working in other hospitals }\end{array}$ & $\begin{array}{c}130 \\
23 \\
0 \\
28\end{array}$ & $\begin{array}{c}85 \\
15 \\
0 \\
18\end{array}$ & $\begin{array}{c}200 \\
211 \\
0 \\
56\end{array}$ & $\begin{array}{c}49 \\
51 \\
0 \\
14\end{array}$ & $\begin{array}{c}2 \\
20 \\
30 \\
6\end{array}$ & $\begin{array}{c}3 \\
28 \\
42 \\
8\end{array}$ & $\begin{array}{c}0 \\
0 \\
82 \\
0\end{array}$ & $\begin{array}{l}\text { NA } \\
\text { NA } \\
59 \\
\text { NA }\end{array}$ & $\begin{array}{l}0 \\
0 \\
0 \\
0\end{array}$ & $\begin{array}{l}\text { NA } \\
\text { NA } \\
\text { NA } \\
\text { NA }\end{array}$ & $\begin{array}{c}0.001 \\
0.001 \\
0.001 \\
0.01\end{array}$ \\
\hline $\begin{array}{l}\text { History of COVID-19 } \\
\text { Positive cases } \\
\text { Contact with positive cases } \\
\text { Dismissed cases }\end{array}$ & $\begin{array}{c}7 \\
8 \\
15\end{array}$ & $\begin{array}{c}5 \\
5 \\
10\end{array}$ & $\begin{array}{c}15 \\
6 \\
20\end{array}$ & $\begin{array}{l}4 \\
1 \\
5\end{array}$ & $\begin{array}{c}2 \\
6 \\
10\end{array}$ & $\begin{array}{c}3 \\
8 \\
14\end{array}$ & $\begin{array}{l}1 \\
3 \\
6\end{array}$ & $\begin{array}{l}1 \\
2 \\
4\end{array}$ & $\begin{array}{l}2 \\
4 \\
2\end{array}$ & $\begin{array}{c}6 \\
11 \\
6\end{array}$ & $\begin{array}{l}0.6 \\
0.7 \\
0.4\end{array}$ \\
\hline
\end{tabular}

COPD: chronic obstructive pulmonary disease; COVID-19: coronavirus disease 2019; SARS-CoV-2: severe acute respiratory coronavirus $2 .{ }^{*}$ Categories with 0 (NA) were not included in the analysis. Linear $X^{2}$ test for $p$-values.

Regarding risk factors, $146(18 \%)$ were $>60$ years old, 158 (19\%) reported SAH, 60 (7\%) reported DM, 135 (16\%) were overweight, and $140(17 \%)$ were obese.

According to the comparative analysis (Table 2), we identified a significant proportion of subjects belonging to the category of "other health-care personnel" $>60$ years of age $(54 \%, p=0.001)$, who represented a higher proportion of comorbidities such as SAH (26\%), DM (13\%), and obesity (47\%).

Compared to the other categories, the medical staff reported a higher vaccination rate in the last year $(75 \%$ pneumococcal, $97 \%$ influenza, and $46 \%$ tetanus). Furthermore, this group was the most exposed to COVID attention areas. Over half of the administrative staff $(59 \%)$ who answered the questionnaire worked at home.

No differences were shown between the categories regarding the presentation of the disease and exposure to other contacts. Furthermore, $18 \%$ of the medical staff and $14 \%$ of the nursing staff worked in other hospital centers.

In the chordal plot (Figure 1), it can be observed that safe distance and masks were mostly employed among physicians and nurses. Moreover, most contacts with infected persons were through exposure to other coworkers.

Regarding transportation, medical and nursing staff mainly used cars, while administrative staff and security service providers mainly used public transportation.

\section{Discussion}

The initial assessment of this early cohort of healthcare workers formed at the beginning of phase 2 of the contingency due to the SARS-CoV-2 pandemic in Mexico City demonstrated that prevailing risk factors could create a scenario where infected healthcare workers develop severe complications of the disease.

The Mexican National Health and Nutrition Survey (ENSANUT by its Spanish acronym ${ }^{7}$ estimated a SAH prevalence of $25 \%$ in its last measurement, presenting a higher frequency from the fifth decade of life. Consistent with this estimation, we observed a higher prevalence of comorbidities in the group classified as "other health-care personnel" where more 


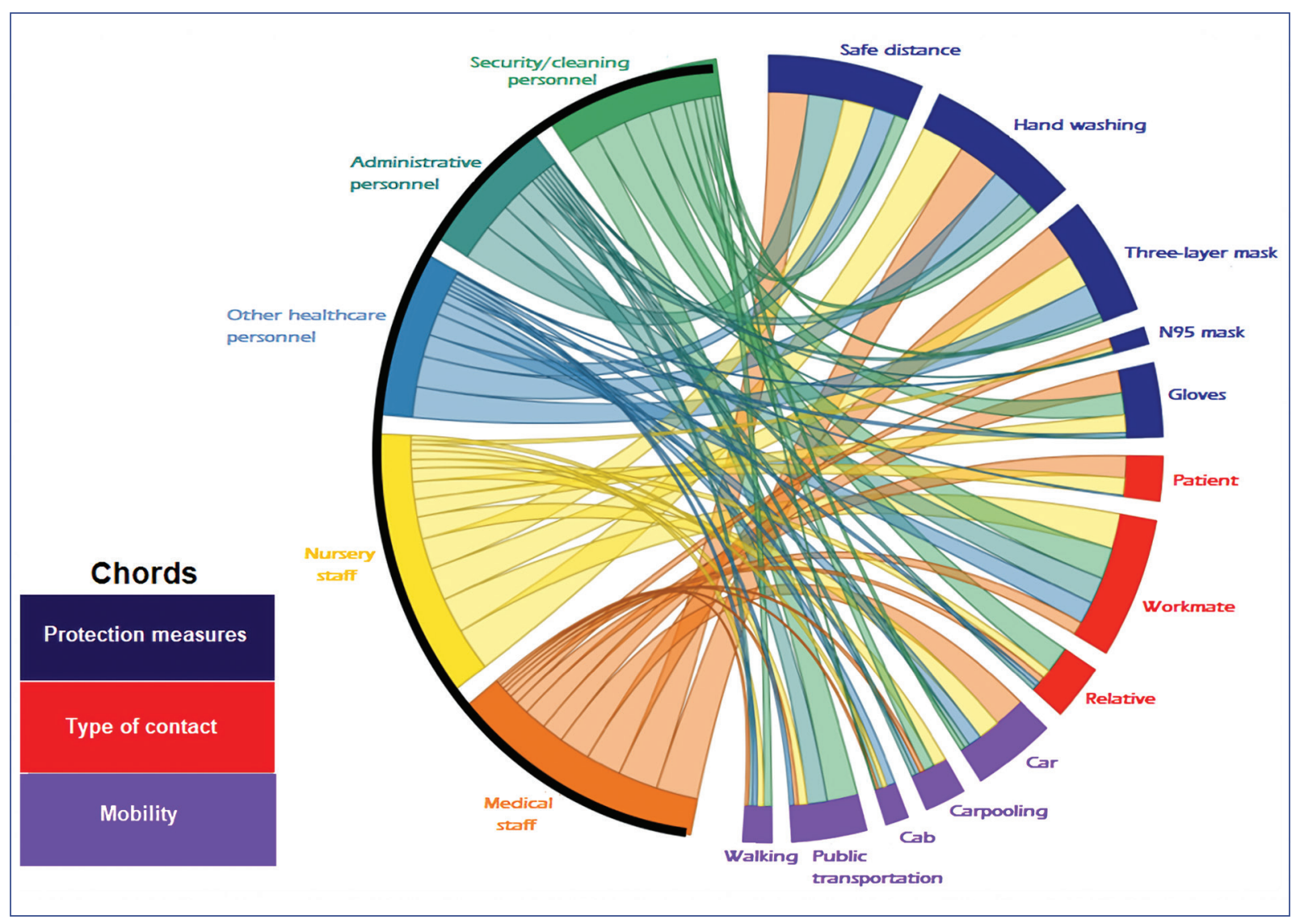

Figure 1. A chordal plot of mobility, contacts, and protection measures against infection of healthcare workers by profession.

than half were over 60 years old. However, $82 \%$ of the cases remained at home. In this regard, international recommendations justify the avoidance of risk areas for healthcare workers with cardiovascular risk factors ${ }^{7}$. This recommendation is relevant because weight control, which is related to overweight, the main cardiovascular risk factor, is a variable that can be modified or controlled to decrease the individual risk $^{8,9}$.

Medical and nursing staff are primarily exposed to direct contact with SARS-CoV-2 infected patients. These groups have high vaccination rates to prevent severe manifestations produced by microbial agents that cause pneumonia, representing a high percentage of patients hospitalized for respiratory infections ${ }^{10}$. These groups also demonstrated a greater frequency in using standard protection measures. Furthermore, the activities of both groups take place within the hospital. A study conducted by Nguyen et al. ${ }^{11}$ showed that healthcare personnel who provide services to SARS-CoV-2 confirmed patients have 11 times more risk of infection $(H R=11.7)$ than those in non-COVID areas $(H R=2.05)$.
Healthcare personnel's education and organization are essential when administering the conditions of the hospital center. Internal movement between areas with and without risk of contagion and the performance of "essential" or "non-essential" tasks depends on schedule planning and the use of protective measures.

In this work, we found that people with administrative positions or people who provide other services use the necessary protection measures (such as hand washing, safe distance, or masks) less frequently ${ }^{10}$.

Healthcare workers at this hospital attend exclusively to a pediatric age population. Mild symptomatic manifestations in children characterize the disease, thus having a lower need for hospitalization. This fact is of great importance because the hospitalization areas have a lower demand for ventilators (compared to COVID hospitals that attend adults). Furthermore, triage areas or emergency rooms that treat respiratory problems are likely to have most of the concentration of potentially infected children, which involves the necessity of adequately assessing the degree of protection that should be present in these areas ${ }^{5}$. 
On the contrary, the fact that children could be asymptomatic carriers represents an important challenge in a hospital that exclusively provides medical care to this population. Consequently, protection measures could be loosened at first, especially by health-care personnel.

Moreover, hospitals cannot control other situations, such as commuting to work (mostly by personal vehicle) and working in different hospitals besides the HIMFG. These situations can also expose healthcare workers to the disease and should be controlled through educational means.

The present study allowed identifying risk factors of personnel who provide health services and planning the location of these personnel in risk areas. The main limitation is collecting data through a questionnaire, which is not free of recall bias and misclassification.

We found a high frequency of comorbidities, such as SAH (19\%), overweight (16\%), and obesity $(17 \%)$ in healthcare workers at a COVID pediatric center, which pose a risk for this disease. Most medical and nursing staff used standard protection measures and had been previously vaccinated for seasonal influenza.

\section{Ethical disclosures}

Protection of human and animal subjects. The authors declare that no experiments were performed on humans or animals for this study.

Confidentiality of data. The authors declare that they have followed the protocols of their work center on patient data publication.

Right to privacy and informed consent. The authors have obtained the written informed consent of the patients or subjects mentioned in the article. The corresponding author has this document.

\section{Conflicts of interest}

The authors declare that they have no conflicts of interest.

\section{Funding}

This project is supported by the program Proyectos de Investigación Científica, Desarrollo Tecnológico e Innovación en Salud Covid-19 (CONACYT), PAACTI/312936.

\section{References}

1. Johns Hopkins University and Medicine. COVID-19 Dashboard by the Center for Systems Science and Engineering (CSSE) at Johns Hopkins University (JHU). Baltimore: Coronavirus Resource Center; 2020. Available from: https://www.coronavirus.jhu.edu/map.html.

2. Wu YC, Chen CS, Chan YJ. The outbreak of COVID-19: an overview. J Chin Med Assoc. 2020;83:217-20.

3. Gan WH, Lim JW, Koh D. Preventing intra-hospital infection and transmission of COVID-19 in healthcare workers. Saf Health Work. 2020;11:241-3.

4. Zhang Z, Liu S, Xiang M, Li S, Zhao D, Huang C, et al. Protecting healthcare personnel from 2019-nCoV infection risks: lessons and suggestions. Front Med. 2020;14:229-31.

5. Bartoszko JJ, Farooqi MA, Alhazzani W, Loeb M. Medical masks vs N95 respirators for preventing COVID-19 in healthcare workers: a systematic review and meta-analysis of randomized trials. Influenza Other Respir Viruses. 2020;14:365-73

6. Secretaría de Salud. Coronavirus, Datos Abiertos. Mexico: Secretaría de Salud México; 2020. Available from: https://www.datos.gob.mx/busca/ dataset/informacion-referente-a-casos-covid-19-en-mexico.

7. Kursumovic E, Lennane S, Cook TM. Deaths in healthcare workers due to COVID-19: the need for robust data and analysis. Anaesthesia. 2020;75:989-92.

8. Mehta S. Nutritional status and COVID-19: an opportunity for lasting change? Clin Med (Lond). 2020;20:270-3.

9. Zhang M, Zhou M, Tang F, Wang Y, Nie H, Zhang L, et al. Knowledge, attitude, and practice regarding COVID-19 among healthcare workers in Henan, China. J Hosp Infect. 2020;105:183-7.

10. Griffin KM, Karas MG, Ivascu NS, Lief L. Hospital preparedness for COVID-19: a practical guide from a critical care perspective. Am J Respir Crit Care Med. 2020;201:1337-44.

11. Nguyen LH, Drew DA, Graham MS, Joshi AD, Guo CG, Ma W, et al. Coronavirus Pandemic Epidemiology Consortium. Risk of COVID-19 among front-line health-care workers and the general community: a prospective cohort study. Lancet Public Health. 2020;5:e475-e483. 